Article

\title{
Disease Management and Estimated Effects on DON (Deoxynivalenol) Contamination in Fusarium Infested Barley
}

\author{
Gregory McKee ${ }^{1, *}$, Christina Cowger ${ }^{2}{ }^{(0)}$, Ruth Dill-Macky ${ }^{3}$, Andrew Friskop ${ }^{4}$, \\ Pravin Gautam ${ }^{5}$, Joel Ransom ${ }^{6}$ and William Wilson ${ }^{7}$ \\ 1 Department of Agricultural Economics, University of Nebraska, Lincoln 204A Filley Hall, Lincoln, \\ NE 68583, USA \\ 2 United States Department of Agriculture-Agricultural Research Service, Department of Plant Pathology, \\ Raleigh, NC 27695, USA \\ 3 Department of Plant Pathology, University of Minnesota, Saint Paul, MN 55108, USA \\ 4 Department of Plant Pathology, North Dakota State University, Dept. 7660, Fargo, ND 58108-6050, USA \\ 5 North American Wheat Breeding \& Operation, BASF Agricultural Solutions, Beaver Crossing, \\ NE 68313, USA \\ 6 Department of Plant Sciences, North Dakota State University, Dept. 7660, Fargo, ND 58108-6050, USA \\ 7 Department of Agribusiness and Applied Economics, North Dakota State University, Dept. 7610, Fargo, \\ ND 58108-6050, USA \\ * Correspondence: Gmckee3@unl.edu; Tel.: +1-402-472-2034
}

Received: 8 June 2019; Accepted: 10 July 2019; Published: 13 July 2019

check for updates

\begin{abstract}
Fusarium head blight (FHB or scab) economically devastates barley production. FHB is predominantly caused by Fusarium graminearum and has resulted in major reductions in the quality of barley in the United States. The most common source of economic loss is through development of potent mycotoxins in the grain, the most prominent of which, in the United States, is deoxynivalenol (DON). DON levels can be managed through a variety of techniques. This study presents the estimate of the statistical relationship among DON contamination in barley, FHB incidence and severity, and a variety of disease management techniques. Data from 22 field studies and a survey of barley producers are used to estimate the relationship. Fungicide applications reduce DON in barley in general and via complementary interactions with the barley cultivar. Genetic FHB resistance in barley varieties is an important determinant of DON levels, as well as previous crop and factors related to time and location. Taking care to avoid rotations with FHB host crops immediately prior to barley is also important to reduce DON levels in barley. These become key inputs into barley producer decisions for evaluating the economic value of adopting FHB management techniques.
\end{abstract}

Keywords: Fusarium head blight; scab; deoxynivalenol; regression; disease management

\section{Introduction}

Fusarium head blight (FHB or scab), primarily caused by infestation of Fusarium graminearum, is one of the most important small grain diseases in the United States. Contamination of the grain by mycotoxins, caused by the pathogen, reduces grain quality [1]. Yield reductions in barley are often not as severe as in wheat. This is often explained by resistance in spring barley where the pathogen does not spread vertically within the grain spike. The greatest economic consequence in barley from FHB occurs when malt quality standards are not met due to the accumulation of mycotoxins, especially deoxynivalenol (DON). For instance, the presence of DON increases gushing risk in the malting process [2]. The amount of DON in barley can often be higher than would be expected for an equivalent level of FHB in wheat, because of the retention of the lemma and palea which is floret tissue that remains attached to the barley kernel in the harvesting and malting process [3]. An elevated amount of 
DON in barley results in substantial price reductions, downgrading to feed barley, or even rejection for barley producers in the Northern Great Plains. Another consequence occurs when barley producers modify production choices, such as including crops less vulnerable to FHB [4].

Management of FHB caused by F. graminearum relies on an integrated program using genetic resistance, fungicides, and cultural practices such as tillage, adjusting planting dates, and crop rotation. Employment of several management tools together has the greatest effect on decreasing losses due to FHB and DON in wheat $[5,6]$. Breeding resistance towards FHB remains a top priority to prevent economic losses as it holds potential for economical FHB control in barley. Limited host resistance has been an objective of wheat and barley cultivar breeding programs [1]. In wheat, the use of a moderately resistant (low DON accumulating) cultivar with a prothioconazole plus tebuconazole fungicide application when $50 \%$ of the main stems are at full head, currently provides the greatest amount of FHB and DON reduction in the Northern Great Plains [7].

Observations of wheat yield loss from FHB are often reported anecdotally, and generally a statistical relationship between FHB and yield is not contemplated. As stated in Salgad et al. [8], estimating such a relationship requires observations of FHB, DON, yield, test weight, and a proposed model of their relationship. Relationships between grain quality and FHB have been observed [9-11]. These relationships suggest the dollar returns from FHB management practices depend on the interaction among biological and economic factors. Prior research has shown negative statistical relationships between FHB and wheat yield $[8,12,13]$, however, damage from FHB is not always readily apparent in barley yield. Studies have estimated the value of loss associated with disease. Beddow et al. [14] estimated losses associated with wheat rust and estimated the value of rust management research which could offset observed losses.

The economic returns to FHB management depend on biological factors and production choices. The magnitude of these returns can be estimated from statistical models. Uniform treatment data from 136 studies observed between 1995 and 2007 were used by Paul et al. [15] to statistically model test weight effects of six fungicide treatments in soft winter and spring wheat varieties based upon their effects on FHB intensity. Using the FHB index and the wheat yield and quality (incidence) data from 77 studies observed between 1995 and 2007, Madden and Paul [16] statistically modeled the yield (i.e., FHB intensity relationship) and concluded that wheat yield is reduced by $0.038 \mathrm{MT} / \mathrm{ha}$ for each one percent increase in FHB severity as measured by the mean percentage of diseased spikelets per spike. Other studies, including Salgado, Madden and Paul [8], Paul et al. [17] and Paul et al. [18], that estimate the statistical relationship between FHB and grain quality show statistically significant relationships between biological factors [19] and production choices exist. To our knowledge, studies showing statistically significant relationships between biological factors and production choices for FHB and DON, in United States barley production, have not been formally documented. Models of the relationship between FHB in barley and DON under various environmental conditions [20,21] exist. Regional measures of economic impacts of FHB in barley have been generated [22,23].

The aim of this study was to statistically model the relationship between FHB management techniques and DON contamination. Uniform field trial data and observations of actual FHB management technique adoption among agricultural producers were used to estimate the relationship between barley grain quality, which is measured as DON contamination measured in ppm, and FHB management technique use, in the presence of FHB. No assumption was made about the optimality of any single treatment program regardless of the number of practices adopted.

\section{Materials and Methods}

DON levels, under treated and untreated conditions, were observed in field experiments under a variety of management conditions. Observations of scab management decisions by barley producers were made by survey. 


\subsection{Field Study Design and Sampling}

Funding from the United States Department of Agriculture, Agriculture Research Service, through the United States Wheat and Barley Scab Initiative, supported integrated management trials on spring barley from 2008 to 2015 . The objectives of the trials were to evaluate the efficacy of multiple management tools used to suppress FHB and DON and protect yield. Management tools evaluated in the trials included varietal resistance, fungicide applications, and previous crop [24]. Two-row and/or six-row barley varieties were used in the trials and were categorized as either susceptible, moderately susceptible, or moderately resistant based on a cultivar's affinity to accumulate DON (Table 1). The fungicide was categorized as either no fungicide or fungicide (tebuconazole + prothioconazole, Prosaro, Bayer CropScience, applied at 50\% heading at $0.475 \mathrm{~L} / \mathrm{ha}$ ). Previous crop was defined as either a host (including wheat and corn) or nonhost (including canola, dry beans, potatoes, soybean, and sunflower) of Fusarium graminearum. Fusarium graminearum is considered to be a weak pathogen to soybean roots in the Upper Great Plains in the USA. Often this pathogen will be found in combination with other more aggressive Fusarium species on soybeans roots. The soybean roots (potentially harboring F. graminearum) tend to stay below the root surface, and they are rarely able to produce important perithecia that are the primary inoculum source for Fusarium head blight epidemics. Therefore, we do not consider soybean, dry bean and other leguminous crops to be a host for $F$. graminearum.

All trials were conducted in a randomized complete block design with a split-plot or split-split plot arrangement and four replicates. In three factor trials, previous crop served as the main plot, cultivar as the subplot and fungicide as the sub-subplot. In two factor trials, cultivar served as the main plot and fungicide as the subplot. A total of 22 trials were conducted with 1 trial conducted in Minnesota (St. Paul), 16 trials across three locations in North Dakota (Fargo, Finley, and Langdon) and five trials across two locations in South Dakota (Brookings and Volga). Plot dimensions varied by location and ranged from 1.5 to $3 \mathrm{~m}$ wide and 5.5 to $9 \mathrm{~m}$ long. Fungicides were applied using $\mathrm{CO}_{2}$-pressured sprayers fitted with Twinjet XR8002 nozzles mounted forward and backward at 30 to 45 degrees. Fusarium head blight incidence and severity were assessed 10 to 14 days after full-spike emergence in each plot. Incidence was measured as the arcsine of the ratio of symptomatic spikes and the total number of sampled spikes [17]. Severity was measured as the ratio of the average number of FHB-diseased spikelets and the FHB-diseased spikes. An index value for each plot was created by multiplying severity by incidence and dividing by 100 . Mature plots were harvested using a small plot combine (make and model varied by research location). From the harvested plot sample, yield and test weight values were obtained. A $100 \mathrm{~g}$ portion (subsample) of the harvested grain from each plot was sent to a testing lab (North Dakota State University Veterinary Diagnostic Lab or University of Minnesota Veterinary Diagnostic Lab) where gas liquid chromatography methods were used for DON content. A representative subsample was obtained according to guidelines located on the USWBSI website (scabusa.org). In summation, assessments (FHB index values, DON, yield, and test weight) were obtained from 2382 plots (Table 2) and each plot was considered a data point for analysis.

Table 1. Observed barley varieties and associated DON resistance designation.

\begin{tabular}{ccc}
\hline Cultivar & Scab Resistance Category & Barley Type \\
\hline 2ND25276 & S & 2 row \\
ACMetcalf & MS & 2 row \\
CDC Meredith & MS & 2 row \\
CDC Mindon & MS & 2 row \\
Celebration & S & 6 row \\
Conlon & MS & 2 row \\
Eslick & S & 2 row \\
Excel & MS & 6 row \\
\hline
\end{tabular}


Table 1. Cont.

\begin{tabular}{ccc}
\hline Cultivar & Scab Resistance Category & Barley Type \\
\hline FEG65-02 & MR & 6 row \\
Innovation & MS & 6 row \\
Lacey & MS & 6 row \\
Legacy & MS & 6 row \\
M122 & MS & 6 row \\
Merit & S & 2 row \\
ND Genesis & MS & 2 row \\
ND20448 & MS & 6 row \\
ND22421 & S & 6 row \\
ND26036 & S & 6 row \\
Pinnacle & MS row \\
Quest & MR & 6 row \\
Rasmusson & S & 6 row \\
Rawson & S & 2 row \\
Robust & S & 6 row \\
Scarlet & MR & 2 row \\
Stellar-ND & MS & 6 row \\
Tradition & S & 6 row
\end{tabular}

FHB resistance categories assigned according to the cultivar's affinity to accumulate deoxynivalenol (DON): $\mathrm{S}=$ susceptible, $\mathrm{MS}=$ moderately susceptible, $\mathrm{MR}=$ moderately resistant.

Table 2. Number of plots observed, by locations in USA and year.

\begin{tabular}{ccccccccc}
\hline Location & $\mathbf{2 0 0 8}$ & $\mathbf{2 0 0 9}$ & $\mathbf{2 0 1 0}$ & $\mathbf{2 0 1 1}$ & $\mathbf{2 0 1 2}$ & $\mathbf{2 0 1 3}$ & $\mathbf{2 0 1 4}$ & $\mathbf{2 0 1 5}$ \\
\hline St. Paul, MN & & & & 64 & & & & \\
Fargo, ND & & 192 & 192 & 192 & 192 & & 60 & 60 \\
Finley, ND & & & & & 48 & & 48 & 60 \\
Langdon, ND & 288 & 288 & 318 & 144 & & & 36 & 36 \\
$\begin{array}{c}\text { Brookings, SD } \\
\text { Volga, SD }\end{array}$ & 16 & 16 & & 24 & & & & \\
\hline
\end{tabular}

\subsection{Scab Management Survey}

A survey questionnaire was developed that included the question "Which of the following practices do you use in order to reduce the amount of damage by scab?" The questionnaire was provided to wheat and barley growers in the following U.S. states: AR, IL, IN, KS, KY, MD, MI, MN, MS, NE, NY, NC, ND, OH, PA, SD, and VA. A list of barley and wheat producers maintained by the National Agricultural Statistics Service (NASS) was used to draw a sample of 15,895 producers from these states. In each state, NASS selected a stratified sample to represent all sizes of wheat and barley operations, and all geographic production regions of the state. To produce a sample meeting all those criteria, a larger percentage of operations was selected in states with fewer operators.

Respondents were provided five techniques for managing FHB as possible options from which to choose which were the following: (1) "grow moderately resistant varieties", (2) "apply a recommended fungicide with scab (FHB) as the primary target at heading (for barley)", (3) "rotate so that I never or rarely grow wheat immediately following another small grain or corn crop", (4) "grow varieties that head at different times", and (5) "stagger planting dates so that the crop does not all flower on the same date". Respondents were free to select as many techniques as they believed applied to their situation. No effort was made to audit the actual use of the selected set of techniques; it is possible that any set of techniques indicated by respondents was aspirational. The question was unaccompanied by statements suggesting or indicating the most effective combination of management techniques. 
The NASS mailed the questionnaires to the producers in 2014. Some respondents mailed completed questionnaires directly to the NASS, but most respondents were surveyed by telephone enumerators. After removing incomplete responses that were unsuitable for statistical analysis, there were a total of 5107 useable reports, which reflected an overall response rate of $32 \%$.

\subsection{Statistical Analyses}

Statistical analysis was used to explain relationships between plant disease management and associated yield or yield quality [25-28], as done previously in wheat and barley [8,29-32]. A mixed effects model was made for the relationship between DON production and FHB presence [33,34]. Plot location and year were considered fixed effects. Weather observations were not made during field trials and were considered random. Coefficients were estimated for locations and varieties to detect the significance and magnitude of the relationship between DON level in barley, cultivar, disease pressure, FHB incidence, FHB severity, and disease management techniques. The following statistical model was considered.

$$
\begin{gathered}
\operatorname{DON}_{t}=\varphi_{1} \text { Fungicide }+\sum_{i=1}^{N} \delta_{i}\left(\text { cultivar }_{i} \times \text { fungicide }\right)+\varphi_{2} \text { Resistance }+ \\
\varphi_{3} \text { PreCrop }+\varphi_{4} \text { Incidence }+\varphi_{5} \text { Severity }+\sum_{i=1}^{P} \delta_{i}\left(\text { cultivar }_{i} \times \text { fungicide } \times \text { disease }_{\text {medium }}\right)+ \\
\sum_{i=1}^{Q} \delta_{i}\left(\text { cultivar }_{i} \times \text { fungicide } \times \text { disease }_{\text {high }}\right)+\mu_{l} \text { Location }+\mu_{t} Y \text { Year }+\varepsilon,
\end{gathered}
$$

where, $N=25, P=8$ (8 cultivars had FHB severity observations in the "medium" range), and $Q=6$ (6 cultivars had FHB severity observations in the "high" range).

$D O N$ was the natural log of the observed deoxynivalenol, as measured in ppm, present in the grain. DON level observations were then standardized relative to the mean and standard deviation of DON ppm observed in the sample. The STANDARD Procedure of SAS (Version 9.4, Cary, North Carolina, NC, USA) was used to standardize the data. Equation 1 was fitted using the REG Procedure in SAS (Version 9.4, Cary, North Carolina, NC, USA). Estimates for the values of $\varphi_{i}, \delta_{i}, \mu_{l}$, and $\mu_{t}$ after fitting Equation 1 to the field trial and survey data indicated the marginal change in standardized DON level, relative to the average, when a one-unit change occurs in exogenous variables.

A null hypothesis for this study was that no overall relationship exists between fungicide applications, either in general or in combination with a given barley cultivar, and DON level in barley. The presence, or absence $(1=$ yes, $0=$ no), of a fungicide application was denoted by the variable Fungicide. This variable represents the overall effect of fungicide applications on DON levels in barley, regardless of other conditions. A significant coefficient for this variable was used to reject the hypothesis that there is no overall effect of fungicide applications on DON in barley.

The DON contamination-FHB presence relationship was hypothesized to be distinct for each cultivar-fungicide combination. An interactive relationship between FHB and fungicide applications to the observed cultivar was hypothesized to affect expected DON levels. Dummy variables $\left(\delta_{i}\right)$ were included in Equation 1 for each cultivar-fungicide combination. The general form for any of the 25 cultivar-fungicide combinations appears in Equation 1 as cultivar $\times$ fungicide. Significant coefficients for any dummy variable representing a cultivar and fungicide interaction were used to reject the null hypothesis that no distinct level of DON is expected for any of the 25 observed cultivars (Table 1) when fungicide is applied (an application of tebuconazole + prothioconazole, Prosaro, Bayer CropScience, applied at 50\% heading at $0.475 \mathrm{~L} / \mathrm{ha}$ ). Uniform field trial data existed for fungicide applications to all 25 observed cultivars.

FHB resistance was observed in the field trial data and an assessment of the cultivar's resistance ( $\mathrm{S}$ = susceptible, MS = moderately susceptible, MR = moderately resistant; no resistant varieties were observed) was made. The description of a given cultivar's FHB resistance was classified in the variable Resistance ${ }_{i}$. A significant coefficient for Resistance ${ }_{i}$ was used to reject the null hypothesis that no relationship between FHB resistance and DON level was present in the data. 
PreCrop is a dummy variable indicating whether the previous crop was a host of $F$. graminearum. Incidence was measured as the arcsine of the ratio of FHB symptomatic spikes and the total number of sampled spikes [17]. We hypothesized that a distinct relationship between FHB incidence and DON existed when incidence is observed between 1.0 and 2.1. Equation 1 contains a dummy variable, Incidence, to test this hypothesis.

FHB severity was calculated as the arcsine of the ratio of symptomatic spikelets per diseased spike and the total number of diseased spikes sampled [17]. Observations of severity were categorized in this study subjectively to test the hypothesis that DON level is affected by disease development in the sample. Observations of severity were categorized low if observed FHB severity was among the lowest 10 percent of observations; observations of severity were categorized as medium if observed FHB severity was between the 10.1 to 74.9 percentiles of observations; and observations of severity were categorized as high if observed FHB severity was among the largest quartile of severity observations. For purposes of avoiding perfect collinearity among the values of Severity when estimating Equation 1 the low Severity case was dropped from the equation. Significant coefficients for the independent variable Severity tested the hypothesis that distinct DON levels occur, relative to the average, under different FHB severity for the observed barley cultivar.

Disease $_{i}$ was a dummy variable used to indicate disease development as determined by the visual assessment of FHB severity and is used for analysis purposes. For purposes of this study, low disease pressure refers to observed values of Severity within the lowest $10 \%$ of all observations; medium disease pressure refers to observed values of Severity within the $10.1 \%$ to $74.9 \%$ of observations; high disease pressure refers to observed values in the largest $25 \%$ of observations. Low, medium, or high levels of FHB development, as described by FHB severity, are not formally defined in the literature.

The heterogeneity of environmental conditions associated with the 22 studies used in this analysis were controlled for in Equation 1 by the fixed effects for location. Locations where field observations were made (Table 2) are denoted generally in Equation 1 by the variable Location. The year field observations were recorded and represented by values of Year, controlled for by a fixed effect designed to capture year-specific field conditions. Significant coefficients for Year were used to reject the null hypothesis that no relationship exists between the unique conditions of any given year of observations and DON level. The term, $\varepsilon$, was an error term distributed based on a normal distribution with mean 0 and variance related to field locations.

Observations of FHB management choices by barley producers were one draw from the theoretical distribution of FHB management choices producers may make. In addition, field conditions were not observed in the NASS survey. The likelihood that a producer adopted any one combination of FHB management practices was unknown. In order to simulate variations in DON levels in barley production conditions, field trial observations of DON contamination under various FHB management conditions were weighted by observed producer frequencies of adopting any combination of FHB management practices, as observed in the NASS survey. All data from field trials, wherein a given combination of FHB management practices was observed, were matched with corresponding producer responses using the same combination of management practices. Since multiple field trial observations are present in the 22 trials for any combination of FHB management practices adopted by producer-respondents, any observed field trial FHB condition associated with a management technique combination was replicated as an independent Bernoulli trial $(0=$ an FHB management combination is not chosen, $1=$ an FHB management combination is chosen), which is a method used to model the incidence and management of disease in other settings [35-39]. Each observation of any field trial condition, for a given combination of FHB management practices, was replicated until the frequency of the field observation equaled the frequency of the management combination in the NASS survey. The parameter value $\alpha_{i}$, where $i$ referred to the frequency of the FHB management combination of management practices one through five listed above, was the assigned weight to each field observation-questionnaire FHB management combination. A DO loop in a SAS DATA step was used to replicate all the possible combinations of NASS-observed producer response with field trial conditions until the frequency of 
any producer-adopted FHB management practice combination was the same as in the NASS survey. Discussion of results was based on estimated coefficients using data simulated from the 2382 plots observed in 22 trials conducted in Minnesota (St. Paul), North Dakota (Fargo, Finley and Langdon), and South Dakota (Brookings and Volga) between 2008 and 2015 (Table 2).

\section{Results}

Producer responses to the survey conducted by the NASS generated observations of the probability any producer selected any of the five management practices. The parameter $\alpha_{i}$, where $i$ refers to the FHB management practices one through five listed above, was defined as the proportion of respondents indicating they used the associated practice. Parameter values, equal to the proportion of producer responses, were as follows: $\alpha_{1}=0.52$ (growing moderately resistant varieties), $\alpha_{2}=0.29$ (applying a recommended fungicide with scab (FHB) as the primary target at full heading), $\alpha_{3}=0.45$ (rotating crops so that growing barley rarely or never follows another small grain or corn crop), $\alpha_{4}=0.09$ (growing varieties that head at different times), and $\alpha_{5}=0.12$ (staggering planting dates to avoid simultaneous heading).

An examination of multicollinearity among the variables indicated nine (of 57) variables in Equation 1 had correlation of 0.5 or more; all other pairs had lesser correlation values. The nine variables were, as expected, those that included interaction terms. The statistical significance associated with these nine variables was great enough to indicate that collinearity had no practical effect on the significance of the estimated coefficients.

The estimated coefficients of Equation 1 detected and measured marginal changes in DON levels when management activities occurred. Estimated coefficients of Equation 1 appear in Tables 3-5. The estimated coefficients in Table 3 show relationships between biological conditions, FHB management choices, and observed DON. These results show that unique circumstances of location and time were present in the relationship between DON, biological factors, and FHB management.

Table 3. Estimated slope coefficients, location, and time fixed effects, Equation (1).

\begin{tabular}{ccccc}
\hline Parameter & Estimate & Std. Error & $t$ Value & $p$-Value \\
\hline Fungicide & -0.2103 & 0.0100 & -21.10 & $<0.0001$ \\
Resistance & 0.0463 & 0.0017 & 26.77 & $<0.0001$ \\
Incidence & 0.1839 & 0.0016 & 113.39 & $<0.0001$ \\
Severity & 0.0446 & 0.0019 & 23.55 & $<0.0001$ \\
PreCrop & 0.1109 & 0.0013 & 86.08 & $<0.0001$ \\
Brookings fixed effect & -0.6362 & 0.0045 & -142.32 & $<0.0001$ \\
Fargo fixed effect & -0.3019 & 0.0028 & -109.37 & $<0.0001$ \\
Finley fixed effect & -0.6309 & 0.0029 & -215.49 & $<0.0001$ \\
Langdon fixed effect & -0.5996 & 0.0029 & -206.44 & $<0.0001$ \\
St Paul fixed effect & 0.9114 & 0.0047 & 194.23 & $<0.0001$ \\
Volga fixed effect & 1.4299 & 0.0056 & 257.06 & $<0.0001$ \\
2008 fixed effect & 0.0097 & 0.0033 & 2.94 & 0.0033 \\
2009 fixed effect & 0.1566 & 0.0031 & 50.57 & $<0.0001$ \\
2010 fixed effect & 0.4417 & 0.0030 & 146.56 & $<0.0001$ \\
2011 fixed effect & 0.5547 & 0.0030 & 182.87 & $<0.0001$ \\
2012 fixed effect & 0.1207 & 0.0030 & 39.95 & $<0.0001$ \\
2013 fixed effect & 0.0281 & 0.0063 & 4.43 & $<0.0001$ \\
2014 fixed effect & 0.0078 & 0.0033 & 2.35 & 0.0189 \\
\hline
\end{tabular}

${ }^{1}$ Parameter estimates are defined as the marginal, or incremental, effect of the observed variable on DON (ppm) in barley. The value of the coefficient is the change in the standardized value of DON, relative to the sample, from a one unit change in exogenous variables, i.e., biological conditions or FHB management choices, observations in a given location (e.g., Fargo), observations in a given year (e.g., 2009). 
The Fungicide variable, estimating the intercept change on estimated DON levels from fungicide applications designed to control FHB, was negative and significant $(p<0.0001$, Table 3$)$. Its value indicated that fungicide use at heading decreases observed DON by $0.19 \mathrm{ppm}$, relative to the standardized average.

The variable Resistance was positive and significant $(p<0.0001)$. Fitting Equation 1 to the data in our sample, and the associated simulations, indicated a decision to adopt barley varieties with increased resistance, all else equal, resulted in a marginal increase in DON of 0.04 ppm relative to the standardized average level of Resistance across all observed cultivars. This result does not necessarily vary from existing literature. Bondalapati, Stein, Neate, Halley, Osborne and Hollingsworth [20] leave the relationship between DON and FHB resistance an open question. Bai and Shaner [40] suggest the limited genetic resistance to FHB available in barley is inconsistent in its effect on DON in barley. Cowger et al. [41] observe variability in DON across a sample of 16 commercial barley varieties, with a range of DON resistance. Moreover, recent work highlights the difficulty of quantifying DON resistance in barley [42]. Furthermore, the field data used for this study included two trials using MR class varieties out of three under high disease, four MS class varieties under medium disease, and two of five $S$ class varieties under high pressure. This combination of factors may have served to generate the observed estimated Resistance coefficient.

Arcsin Incidence and arcsin Severity had a statistically significant $(p<0.0001)$, and positive, relationship on DON in barley. The estimated arcsin Incidence coefficient indicated an observation of the arcsin of average FHB incidence within the 0.9 to 1.2 range increased DON by $0.19 \mathrm{ppm}$. Comparing an observation of the arcsin scab Severity from outside, to within, the 0.1 to 0.2 range was expected to increase DON by $0.04 \mathrm{ppm}$ as compared with the standardized average. A change of FHB arcsin Incidence into the 0.9 to 1.2 range had, by comparison, a larger effect on DON contamination in barley. As expected, the PreCrop variable was also positive and statistically significant.

The null hypothesis that no relationship between year of observation and location of observation was rejected. The fixed effect coefficients for Brookings, Fargo, Finley, and Langdon were statistically significant and negative $(p<0.0001$, Table 3); whereas the coefficients for St. Paul and Volga were statistically significant and positive ( $p<0.0001$, Table 3). Although data from 2008 to 2015 were used to estimate Equation 1, estimated coefficients for dummy variables for years 2008 through 2014 are shown; 2015 was dropped to avoid perfect collinearity among the year variables. Values for 2008 through 2014 were statistically significant and positive, indicating observations in these years were expected to have greater DON $(p<0.0001$, Table 3$)$ than other years in the sample.

In summary, a statistically significant relationship existed between plant conditions (FHB incidence and severity), FHB management choices (whether a fungicide application is made, rotating crops so that barley does not follow a suitable F. graminearum host) and observed DON. The magnitude of this relationship was related to time- and location-specific factors.

The results of Equation 1 (Table 4) also show that a complex relationship existed between fungicide applications, barley cultivars, and DON levels. Estimated coefficients of interaction term variables for selected barley varieties and management techniques were statistically significant (see Table 1 for the description of cultivar resistance) $(p<0.0001$, Table 4$)$ when simulated data are considered. The estimated coefficients for all cultivars are presented in Table 4 . The estimated coefficients for ten cultivars were negative and significant. The cultivar Tradition was dropped from the model so as to avoid perfect collinearity among the cultivar-fungicide interaction term variables.

The complexity of the relationship between fungicide applications, barley cultivars, and DON levels was influenced by FHB severity. Eleven estimated interaction term coefficients, representing eight cultivars, were positive and significant when the interaction term includes disease, cultivar, and fungicide applications (Conlon, Merit, ND20448, Pinnacle, Quest, Rawson, Scarlet, and Tradition). For three cultivars, at medium disease (M122, ND20448, and Robust) the interaction terms were negative and significant $(p<0.0001$, Table 5). The sign on the coefficients of the parameters for these three cultivars was reversed when a comparison with fungicide-cultivar interaction was considered (Table 4). 
For five cultivars (Conlon, Merit, Pinnacle, Quest, and Scarlet), a negative coefficient when fungicide applications were considered alone was reversed when the fungicide-cultivar-disease interaction term was considered. The estimated coefficients of none of the interaction terms were observed to always be less than the average regardless of whether fungicide applications were considered with disease conditions. These results imply that barley growers cannot overlook interactions of FHB severity and cultivar when considering the consequences of fungicide applications on DON level in barley.

Table 4. Estimated intercept coefficients, interaction terms with cultivars and fungicide application.

\begin{tabular}{ccccc}
\hline Parameter $^{1}$ & Estimate & Std. Error & $\boldsymbol{t}$ Value & $p$-Value \\
\hline 2ND25276 & -0.4148 & 0.0164 & -25.35 & $<0.0001$ \\
ACMetcalf & 0.2684 & 0.0110 & 24.44 & $<0.0001$ \\
CDC Meredith & -0.0013 & 0.0229 & -0.06 & 0.9541 \\
CDCMindon & 0.8849 & 0.0138 & 64.25 & $<0.0001$ \\
Celebration & 0.5524 & 0.0116 & 47.62 & $<0.0001$ \\
Conlon & -0.5959 & 0.0149 & -40.10 & $<0.0001$ \\
Eslick & 0.7324 & 0.0140 & 52.35 & $<0.0001$ \\
Excel & 0.7735 & 0.0142 & 54.37 & $<0.0001$ \\
FEG65-02 & -0.2077 & 0.0139 & -14.95 & $<0.0001$ \\
Innovation & 0.1675 & 0.0155 & 10.79 & $<0.0001$ \\
Lacey & 0.2929 & 0.0121 & 24.11 & $<0.0001$ \\
M122 & 0.3557 & 0.0124 & 28.65 & $<0.0001$ \\
Merit & -0.5250 & 0.0135 & -39.00 & $<0.0001$ \\
ND Genesis & -0.2618 & 0.0148 & -17.69 & $<0.0001$ \\
ND20448 & 0.7481 & 0.0129 & 58.09 & $<0.0001$ \\
ND22421 & 0.1132 & 0.0148 & 7.65 & $<0.0001$ \\
ND26036 & -0.2394 & 0.0165 & -14.55 & $<0.0001$ \\
Pinnacle & -0.5427 & 0.0147 & -36.90 & 0.388 \\
Quest & -0.0092 & 0.0107 & -0.86 & $<0.0001$ \\
Rasmusson & 0.4042 & 0.0121 & 33.50 & $<0.0001$ \\
Rawson & -0.2009 & 0.0109 & -18.46 & $<0.0001$ \\
Robust & 0.4789 & 0.0114 & 41.89 & $<0.0001$ \\
Scarlet & -0.3118 & 0.0173 & -18.03 & $<0.0001$ \\
Stellar-ND & 0.1484 & 0.0154 & 9.61 &
\end{tabular}

1 Parameter estimates are defined as the marginal, or incremental, effect of the observed variable on DON (ppm) in barley. The value of the coefficient is the change in the standardized value of DON, relative to the sample, from a one unit change in exogenous variables, i.e., planting cultivar Excel as compared with cultivar Robust.

Table 5. Estimated intercept coefficients, interaction terms with cultivars and fungicide application, by FHB severity category.

\begin{tabular}{|c|c|c|c|c|}
\hline Parameter ${ }^{1}$ & Estimate & Std. Error & $t$ Value & $p$-Value \\
\hline Conlon $\mathrm{X}$ med. disease & 0.8833 & 0.0128 & 68.76 & $<0.0001$ \\
\hline Conlon $\mathrm{X}$ high disease & 0.5273 & 0.0120 & 43.94 & $<0.0001$ \\
\hline M122 X med. disease & -0.1175 & 0.0129 & -9.11 & $<0.0001$ \\
\hline Merit X med. disease & 1.5479 & 0.0139 & 111.07 & $<0.0001$ \\
\hline ND20448 X med. disease & -0.4564 & 0.0097 & -46.96 & $<0.0001$ \\
\hline Pinnacle $X$ med. disease & 1.1052 & 0.0143 & 77.11 & $<0.0001$ \\
\hline Pinnacle $X$ high disease & 1.7371 & 0.0154 & 112.93 & $<0.0001$ \\
\hline Quest X high disease & 0.1333 & 0.0093 & 14.30 & $<0.0001$ \\
\hline Rawson $\mathrm{X}$ high disease & 0.5649 & 0.0079 & 71.64 & $<0.0001$ \\
\hline Robust $X$ med. disease & -0.4586 & 0.0070 & -65.27 & $<0.0001$ \\
\hline Scarlet $X$ med. disease & 0.0769 & 0.0151 & 5.07 & $<0.0001$ \\
\hline Scarlet $\mathrm{X}$ high disease & 0.5941 & 0.0160 & 37.15 & $<0.0001$ \\
\hline Tradition $X$ med. disease & 0.1453 & 0.0107 & 13.63 & $<0.0001$ \\
\hline Tradition $\mathrm{X}$ high disease & 0.8418 & 0.0129 & 65.10 & $<0.0001$ \\
\hline
\end{tabular}

1 Parameter estimates are defined as the marginal, or incremental, effect of the observed variable on DON (ppm) in barley. The value of the coefficient is the change in the standardized value of DON, relative to the sample, from a one unit change in exogenous variables, i.e., assessing the effect of fungicide applications on cultivar Pinnacle under medium as compared with high FHB severity. 


\section{Discussion}

This study examined the marginal effects of scab management techniques on the occurrence of DON in barley. Marginal effects were estimated based on data from field experiments under a variety of management conditions and based on data from observed scab management decisions by barley producers. Selected marginal effects, modeled as interaction terms in a statistical model, were estimated for interactions of fungicide, barley cultivar, and FHB severity. The interpretation of these interaction term coefficients should be made with care. A positive interaction term coefficient for a barley cultivar indicated average DON is greater, on the margin, for these varieties under treatment conditions. The fitted results indicate 13 (Table 3) observed barley varieties observed in the field trials have greater expected DON levels than average (see Table 1 for description of cultivar resistance) when fungicide applications are made.

Results from Tables 3-5 can be used to forecast DON levels for any specific cultivar, such as for FEG65-02, under various FHB management and field conditions. In this case, evaluating the model for FEG65-02 at average conditions for resistance, incidence, severity, previous crop, and planted in Brookings in 2013, generated a standardized estimate of $-0.86 \mathrm{ppm}$, or $0.21 \mathrm{ppm}$ (unstandardized). By comparison, evaluating the model for the cultivar Celebration resulted in an estimated increase in DON of $-0.10 \mathrm{ppm}$ (standardized) relative to the standardized average; when unstandardized, this was a marginal effect of $0.19 \mathrm{ppm}$.

Statistically significant interaction terms indicate cultivar, fungicide application, and disease presence interact to affect DON levels. Results identified five cultivars wherein a marginally significant increase in DON (Table 5), under moderate disease (approximately the middle 60 percent of observed severity), was inferred. Similarly, DON was greater, at the margin, for six varieties under high disease conditions (top 25 percent of observed FHB severity) while two had less than average. The greatest increase in DON, relative to average fungicide treated varieties, was observed in the cultivar Merit with a moderate level of disease and the cultivar Pinnacle under high disease; alternatively we observed the greatest decrease in DON, in fungicide treated varieties, for the cultivar Robust under moderate disease. All other varieties, as indicated by the absence of a statistically significant coefficient, would be expected to have DON levels similar to the average of varieties observed in this sample in 2008 or later under medium or high disease. These results suggested that the barley producers should consider benchmark FHB present at the time of a fungicide application as a factor for expected DON contamination management.

Care should be taken in interpreting the meaning of the Fungicide coefficient in the viability of fungicide use as a means to reduce DON levels in barley. The negative estimated coefficient of the variable Fungicide alone indicated a fungicide application reduced, on the margin, average DON. However, the effect of fungicide applications, as observed in this sample, occurred in complementarity with barley varieties and disease. Almost all observed cultivars, as indicated by the statistical significance of the fungicide and cultivar interaction terms, had a complementary effect with fungicide (Tables 4 and 5). In other words, production decisions (whether to make fungicide applications) as well as biological conditions (FHB development) interact to influence DON levels in barley. The results showed that the economic viability of fungicide applications was affected by particular cultivars. In addition, the pretreatment FHB incidence and severity can contribute to the economic returns from an application. We note, in particular, the relatively greater consequences of management, collectively, on FHB incidence as compared with FHB severity. For instance, a complex relationship between mycotoxin production and disease, when fungicide applications were made, was observed for several cultivars observed in the sample obtained for this study (Table 5). Barley producers should be aware of the complex relationship between fungicide and cultivars.

The estimated total change of DON levels by FHB management decisions was forecast by considering the interactive effect of production decisions and biological conditions. The combination of FHB management and biological conditions can be evaluated, for instance, on cultivar Conlon as the sum of the intercept, the interaction term for Conlon and a fungicide application, the interaction term 
for a fungicide application and medium disease, and the intercept term for a fungicide application. Evaluating the model under these conditions, under average biological conditions, resulted in an expected (standardized) $-0.70 \mathrm{ppm}$ of DON (0.08 ppm unstandardized). Similarly, evaluating the model for cultivar Merit, under the same biological conditions, resulted in a DON decrease of (standardized) $-0.63 \mathrm{ppm}$ (0.09 ppm unstandardized). The apparent differences in expected marginal changes, as illustrated by comparing the results of Conlon and Merit, indicated the dollar value of fungicide applications varies substantially, but that foregone applications of these applications would result in losses.

Field trials used in this study were made under conditions of distinct, subjective, resistance to FHB. Results indicated the consequence of a unit increase in cultivar resistance to FHB, by planting a cultivar of resistance category MS instead of $S$, diminished about one-sixth of the marginal effect of a fungicide application. The economic viability of using genetic resistance as a management technique can be estimated using the fitted results from Equation 1 . The marginal effect of resistance, based on the sample, was obtained by observing the estimated coefficient on Resistance. The positive 0.05 (Table 3) indicated the average DON increased by $0.05 \mathrm{ppm}$ (standardized) after increasing FHB resistance by one unit. This result must, however, be interpreted as a partial effect, within the context of the field sample obtained from the twenty-two studies. The effect of a change in Resistance (e.g., from "susceptible" to "moderately susceptible") on DON was complementary with the cultivar (which must be present) and disease development, and it is typically combined with a fungicide treatment whose target is FHB control. When the effect of resistance, in cultivars treated with a fungicide, is evaluated, the complementarity of the results indicates a positive economic viability for a FHB treatment program. According to Johnson and Nganje [43], discounts of $\$ 0.50$ per point are applied for DON levels between 0.6 and $1.0 \mathrm{ppm}$ and no discount is applied below $0.5 \mathrm{ppm}$. Hence, management programs may result in savings per bushel. Furthermore, the complementarity of the management activities on DON levels, through reduced incidence, results in a reduced number of damaged barley spikes.

\section{Conclusions}

Statistical relationships were estimated between barley DON contamination, the level of FHB, and use of disease management techniques including fungicide applications, cultivar choice, and cultivar resistance. We used uniform field data from 22 studies of FHB management in barley observed between 2008 and 2015, and FHB management survey responses from agricultural producers observed in 2014, to study the consequences of foregone FHB management on DON levels in barley. We found, using a statistical model of the relationship between biological conditions and FHB management decisions on DON levels in barley, that FHB management techniques mitigated DON levels in barley. The practical significance of this results is that inferences can be made about the changes in DON contamination via FHB management in barley.

Our findings indicated barley cultivar, genetic FHB resistance in barley, fungicide applications with FHB management as their target, FHB severity and incidence, disease pressure, location, and year are statistically significant in their influence on DON levels in barley. Environmental conditions specific to location and year of observations significantly affected DON levels. These results indicated a unique relationship exists between DON level, location, and/or uniqueness in each of the crop years. For example, this may reflect unique patterns of FHB disease development. Fungicide applications are one of the most important determinants of DON levels in barley and had the effect of reducing DON in barley. More importantly, the magnitude of the fungicide effect on DON levels was moderated via interactions with the barley cultivar, i.e., its impact varied across varieties. Additionally, genetic FHB resistance in barley varieties was important, and, furthermore, complementarity exists between cultivar and fungicide use. On the margin, the effect of FHB resistance on DON in barley was positive, based on fitting the statistical model to data from our selected studies. This cannot be viewed independently of the apparent interactive nature of resistance, disease presence, and cultivar. Finally, FHB incidence and FHB severity were significantly related to barley quality (DON level) in a logical way. 
We acknowledge limitations to our study. Our first concern is with respect to the 22 field studies. The scope of data provided in these studies was the best currently available in terms of observing DON management over time in selected barley varieties. Second, while fungicide applications affect DON levels in a statistically significant way, absent from our study are observations of other important features of this management technique, including application timing (which the significant coefficients for Incidence and Severity suggest is likely to matter), number of fungicide applications, type of fungicide, and so forth. Finally, of concern is the inherent nature of survey responses. Validity of observed management activity adoption distribution may be limited by the potential aspirational nature of responses, which is an issue with any type of self-reporting. These responses were generated based on experiences these producers had. We have attempted to offset possible variations in FHB management outcomes for any observed producer response by simulating actual management behavior. A different set of producer experiences would have generated different weights for our simulation. Furthermore, we note that survey data themselves do not describe outcomes of management activities (e.g., effects on yield or DON).

Author Contributions: Conceptualization, methodology, validation, formal analysis, writing — original draft and review and editing, G.M.; validation, data curation, writing — original draft, writing — review and editing, A.F.; validation, data curation, writing-review and editing, C.C., P.G., J.R., and R.D.-M.; project administration, W.W.

Funding: Salaries and research support were provided by state and federal funds, especially the United States Wheat and Barley Scab Initiative, through a project titled "Economic Impact of USWBSI Impact on Reducing FHB".

Acknowledgments: We acknowledge the assistance of Joy Smith (retired), at the North Carolina State University, Department of Statistics for preparing the FHB management response data. The United States Department of Agriculture National Agricultural Statistics Service collaborated in obtaining the FHB management data.

Conflicts of Interest: The authors declare no conflicts of interest.

\section{References}

1. McMullen, M.; Bergstrom, G.; De Wolf, E.; Dill-Macky, R.; Hershman, D.; Shaner, G.; Van Sanford, D. A unified effort to fight an enemy of wheat and barley: Fusarium head blight. Plant Dis. 2012, 96, 1712-1728. [CrossRef] [PubMed]

2. Virkajärvi, V.; Sarlin, T.; Laitila, A. Fusarium profiling and barley malt gushing propensity. J. Am. Soc. Brew. Chem. 2017, 75, 181-192. [CrossRef]

3. Steffenson, B.J. Fusarium Head Blight of Barley: Impact, Epidemics, Management, and Strategies for Identifying and Utilizing Genetic Resistance; Steffenson, B., Ed.; APS Press: St. Paul, MN, USA, 2003.

4. Wilson, W.; Dahl, B.; Nganje, W. Economic Costs of Fusarium Head Blight, Scab and Deoxynialenol. World Mycotoxin J. 2018, 11, 291-302. [CrossRef]

5. Wiersma, J. Growers' needs and industry wants: A retrospective of two decades in the trenches in the battle with FHB. In Proceedings of the 2016 National Fusarium Head Blight Forum, St. Louis, MO, USA, 6 December 2016; p. 103.

6. Hollingsworth, C.; Motteberg, C.; Wiersma, J.; Atkinson, L. Agronomic and economic responses of spring wheat to management of Fusarium head blight. Plant Dis. 2008, 92, 1339-1348. [CrossRef]

7. Paul, P.; Salgado, J.; Bergstrom, G.; Bradley, C.; Byamukama, E.; Byrne, A.; Chapara, V.; Cummings, J.; Chilvers, M.; Dill-Macky, R. Integrated effects of genetic resistance and prothioconazole + tebuconazole application timing on Fusarium head blight in wheat. Plant Dis. 2018, 103, 223-237. [CrossRef]

8. Salgado, J.; Madden, L.; Paul, P. Quantifying the effects of Fusarium head blight on grain yield and test weight in soft red winter wheat. Phytopathology 2015, 105, 295-306. [CrossRef]

9. Geißinger, C.; Whitehead, I.; Hofer, K.; Heß, M.; Habler, K.; Becker, T.; Gastl, M. Influence of Fusarium avenaceum infections on barley malt: Monitoring changes in the albumin fraction of barley during the malting process. Int. J. Food Microbiol. 2019, 293, 7-16. [CrossRef]

10. Martin, C.; Schöneberg, T.; Vogelgsang, S.; Morisoli, R.; Bertossa, M.; Mauch-Mani, B.; Mascher, F. Resistance against Fusarium graminearum and the relationship to $\beta$-glucan content in barley grains. Eur. J. Plant Pathol. 2018, 152, 621-634. [CrossRef] 
11. Schwarz, P.; Horsley, R.; Steffenson, B.; Salas, B.; Barr, J. Quality risks associated with the utilization of Fusarium head blight infected malting barley. J. Am. Soc. Brew. Chem. 2006, 64, 1-7. [CrossRef]

12. Salgado, J.; Madden, L.; Paul, P. Efficacy and economics of integrating in-field and harvesting strategies to manage Fusarium head blight of wheat. Plant Dis. 2014, 98, 1407-1421. [CrossRef]

13. Wegulo, S.N.; Baenziger, P.S.; Nopsa, J.H.; Bockus, W.W.; Hallen-Adams, H. Management of Fusarium head blight of wheat and barley. Crop Protect. 2015, 73, 100-107. [CrossRef]

14. Beddow, J.M.; Hurley, T.M.; Kriticos, D.J.; Pardey, P.G. Measuring the Global Occurrence and Probabilistic Consequences of Wheat Stem Rust. Available online: http://harvestchoice.org/sites/default/files/downloads/ publications/Beddow_et_al_2013HC-Stem_Rust_Tech_Note(3-19-2013).pdf (accessed on 12 July 2019).

15. Paul, P.; McMullen, M.; Hershman, D.; Madden, L. Meta-analysis of the effects of triazole-based fungicides on wheat yield and test weight as influenced by Fusarium head blight intensity. Phytopathology 2010, 100, 160-171. [CrossRef]

16. Madden, L.; Paul, P. Assessing heterogeneity in the relationship between wheat yield and fusarium head blight intensity using random-coefficient mixed models. Phytopathology 2009, 99, 850-860. [CrossRef]

17. Paul, P.; Lipps, P.; Madden, L. Relationship between visual estimates of Fusarium head blight intensity and deoxynivalenol accumulation in harvested wheat grain: A meta-analysis. Phytopathology 2005, 95, 1225-1236. [CrossRef]

18. Paul, P.; Lipps, P.; Hershman, D.; McMullen, M.; Draper, M.; Madden, L. A quantitative synthesis of the relative efficacy of triazole-based fungicides for FHB and DON control in wheat. In Proceedings of the 2007 National Fusarium Head Blight Forum, The Westin Crown Center Kansas City, MO, USA, 2-4 December 2007; p. 115.

19. Schöneberg, T.; Musa, T.; Forrer, H.-R.; Mascher, F.; Bucheli, T.D.; Bertossa, M.; Keller, B.; Vogelgsang, S. Infection conditions of Fusarium graminearum in barley are variety specific and different from those in wheat. Eur. J. Plant Pathol. 2018, 151, 975-989. [CrossRef]

20. Bondalapati, K.; Stein, J.; Neate, S.; Halley, S.; Osborne, L.; Hollingsworth, C. Development of weather-based predictive models for Fusarium head blight and deoxynivalenol accumulation for spring malting barley. Plant Dis. 2012, 96, 673-680. [CrossRef]

21. Janssen, E.; Liu, C.; Van der Fels-Klerx, H. Fusarium infection and trichothecenes in barley and its comparison with wheat. World Mycotoxin J. 2018, 11, 33-46. [CrossRef]

22. Windels, C.E. Economic and social impacts of Fusarium head blight: changing farms and rural communities in the Northern Great Plains. Phytopathology 2000, 90, 17-21. [CrossRef]

23. Nganje, W.E.; Bangsund, D.A.; Leistritz, F.L.; Wilson, W.W.; Tiapo, N.M. Regional economic impacts of Fusarium head blight in wheat and barley. Rev. Agric. Econ. 2004, 26, 332-347. [CrossRef]

24. Wilson, W.; McKee, G.; Nganje, W.; Dahl, B.; Bangsund, D. Economic Impact of USWBSI's Impact on Reducing FHB; Department of Agribusiness and Applied Economics, North Dakota State University: Fargo, ND, USA, 2017.

25. Bhathal, J.S.; Loughman, R.; Speijers, J. Yield reduction in wheat in relation to leaf disease from yellow (tan) spot and Septoria nodorum blotch. Eur. J. Plant Pathol. 2003, 109, 435-443. [CrossRef]

26. Mehra, L.; Cowger, C.; Ojiambo, P. A model for predicting onset of Stagonospora nodorum blotch in winter wheat based on preplanting and weather factors. Phytopathology 2017, 107, 635-644. [CrossRef] [PubMed]

27. Rios, J.A.; Rios, V.S.; Paul, P.A.; Souza, M.A.; Araujo, L.; Rodrigues, F.A. Fungicide and cultivar effects on the development and temporal progress of wheat blast under field conditions. Crop Protect. 2016, 89, 152-160. [CrossRef]

28. Sevastos, A.; Kalampokis, I.F.; Panagiotopoulou, A.; Pelecanou, M.; Aliferis, K.A. Implication of Fusarium graminearum primary metabolism in its resistance to benzimidazole fungicides as revealed by $1 \mathrm{H}$ NMR metabolomics. Pesticide Biochem. Physiol. 2018, 148, 50-61. [CrossRef]

29. Salgado, J.D.; Lindsey, L.E.; Paul, P.A. Effects of row spacing and nitrogen rate on wheat grain yield and profitability as influenced by diseases. Plant Dis. 2017, 101, 1998-2011. [CrossRef] [PubMed]

30. Paul, P.A.; Bradley, C.; Madden, L.V.; Lana, F.D.; Bergstrom, G.C.; Dill-Macky, R.; Esker, P.; Wise, K.A.; McMullen, M.; Grybauskas, A. Meta-analysis of the effects of QoI and DMI fungicide combinations on Fusarium head blight and deoxynivalenol in wheat. Plant Dis. 2018, 102, 2602-2615. [CrossRef] [PubMed]

31. Willyerd, K.; Bradley, C.; Chapara, V.; Conley, S.; Esker, P.; Madden, L.; Wise, K.; Paul, P. Revisiting fungicide-based management guidelines for leaf blotch diseases in soft red winter wheat. Plant Dis. 2015, 99, 1434-1444. [CrossRef] [PubMed] 
32. Alisaac, E.; Behmann, J.; Kuska, M.T.; Dehne, H.W.; Mahlein, A.K. Hyperspectral quantification of wheat resistance to Fusarium head blight: comparison of two Fusarium species. Eur. J. Plant Pathol. 2018, 152, 869-884. [CrossRef]

33. Prom, L.; Horsley, R.; Steffenson, B.; Schwarz, P. Development of Fusarium head blight and accumulation of deoxynivalenol in barley sampled at different growth stages. J. Am. Soc. Brew. Chem. 1999, 57, 60-63. [CrossRef]

34. Abramson, D.; Clear, R.; Usleber, E.; Gessler, R.; Nowicki, T.; Märtlbauer, E. Fusarium species and 8-keto-trichothecene mycotoxins in Manitoba barley. Cereal Chem. 1998, 75, 137-141. [CrossRef]

35. Chaussalet, T.; Mann, J.; Perry, J.; Francos-Rodriguez, J. A nearest neighbour approach to the simulation of spread of barley yellow dwarf virus. Comput. Electron. Agric. 2000, 28, 51-65. [CrossRef]

36. Lescourret, F.; Blecher, N.; Habib, R.; Chadoeuf, J.; Agostini, D.; Pailly, O.; Vaissière, B.; Poggi, I. Development of a simulation model for studying kiwi fruit orchard management. Agric. Syst. 1999, 59, 215-239. [CrossRef]

37. Passey, T.; Robinson, J.; Shaw, M.; Xu, X. The relative importance of conidia and ascospores as primary inoculum of Venturia inaequalis in a southeast England orchard. Plant Pathol. 2017, 66, 1445-1451. [CrossRef]

38. Mercader, R.; Siegert, N.; McCullough, D. Estimating the influence of population density and dispersal behavior on the ability to detect and monitor Agrilus planipennis (Coleoptera: Buprestidae) populations. J. Econ. Entomol. 2012, 105, 272-281. [CrossRef]

39. Van Maanen, A.; Xu, X. Modelling plant disease epidemics. Eur. J. Plant Pathol. 2003, 109, 669-682. [CrossRef]

40. Bai, G.; Shaner, G. Management and resistance in wheat and barley to Fusarium head blight. Annu. Rev. Phytopathol. 2004, 42, 135-161. [CrossRef]

41. Cowger, C.; Arellano, C.; Marshall, D.; Fitzgerald, J. Managing Fusarium head blight in winter barley with cultivar resistance and fungicide. Plant Dis. 2019, in press. [CrossRef]

42. Kumar, A.; Karre, S.; Dhokane, D.; Kage, U.; Hukkeri, S.; Kushalappa, A.C. Real-time quantitative PCR based method for the quantification of fungal biomass to discriminate quantitative resistance in barley and wheat genotypes to Fusarium head blight. J. Cereal Sci. 2015, 64, 16-22. [CrossRef]

43. Johnson, D.; Nganje, W. Impacts of DON in the Malting Barley Supply Chain: Aggregate Costs and Firm-Level Risks; Department of Agricultural Economics, Agricultural Experiment Station, North Dakota State University: Fargo, ND, USA, 2000.

(C) 2019 by the authors. Licensee MDPI, Basel, Switzerland. This article is an open access article distributed under the terms and conditions of the Creative Commons Attribution (CC BY) license (http://creativecommons.org/licenses/by/4.0/). 